\title{
Oxygen therapy in acute exacerbations of chronic obstructive pulmonary disease
}

This article was published in the following Dove Press journal:

International Journal of COPD

7 November 2014

Number of times this article has been viewed

\section{Simon E Brill \\ Jadwiga A Wedzicha}

Airway Disease Section, National Heart and Lung Institute, Imperial College, London, UK
Correspondence: Simon E Brill Airway Disease Section, National Heart and Lung Institute, Imperial College, Emmanuel Kaye Building, Room G39, Ib Manresa Road, London, SW3 6LR, UK Email s.brill@imperial.ac.uk

\begin{abstract}
Acute exacerbations of chronic obstructive pulmonary disease (COPD) are important events in the history of this debilitating lung condition. Associated health care utilization and morbidity are high, and many patients require supplemental oxygen or ventilatory support. The last 2 decades have seen a substantial increase in our understanding of the best way to manage the respiratory failure suffered by many patients during this high-risk period. This review article examines the evidence underlying supplemental oxygen therapy during exacerbations of COPD. We first discuss the epidemiology and pathophysiology of respiratory failure in COPD during exacerbations. The rationale and evidence underlying oxygen therapy, including the risks when administered inappropriately, are then discussed, along with further strategies for ventilatory support. We also review current recommendations for best practice, including methods for improving oxygen provision in the future.
\end{abstract}

Keywords: chronic obstructive pulmonary disease (COPD), exacerbation, oxygen therapy, respiratory failure, hypercapnia

\section{Introduction}

Chronic obstructive pulmonary disease (COPD) is a global health problem and is expected to be the third leading cause of mortality worldwide by $2020 .{ }^{1}$ It is characterized by persistent airflow limitation and acute episodes of symptom worsening, or exacerbations, that are beyond normal daily variation and that lead to a change in treatment. ${ }^{1}$ Acute exacerbations of COPD are key events and are associated with faster lung function deterioration, ${ }^{2}$ worsened health status, ${ }^{3}$ and increased mortality. ${ }^{4,5}$ Impaired gas exchange leading to hypoxemia is an important feature of $\mathrm{COPD}^{6}$ and is likely to underlie many of its pathophysiological consequences.

While the use of supplemental oxygen in stable disease carries a poor prognosis, it remains one of the few evidence-based interventions to improve mortality. However, although hypoxemia worsens at exacerbation, ${ }^{8}$ there is increasing evidence that injudicious use of oxygen is also dangerous.

This review article will examine the pathophysiology and clinical features of hypoxemia in exacerbations of COPD, as well as the evidence and recommendations for supplemental oxygen therapy.

\section{Definitions}

Oxygen therapy is defined as oxygen given at concentrations greater than that found in the surrounding air. It is used as a treatment for respiratory failure, itself defined as an inability of the lungs and respiratory apparatus to ensure adequate systemic oxygenation 
and/or carbon dioxide excretion. This is further classified by whether there is a failure of oxygenation (a low partial pressure of oxygen $\left[\mathrm{PaO}_{2}\right]$ ) with a normal partial pressure of carbon dioxide $\left(\mathrm{PaCO}_{2}\right.$, "type 1 " respiratory failure), or whether the $\mathrm{PaCO}_{2}$ is high ("type 2," or hypercapnic, respiratory failure). Another important variable is whether acidosis is present as a consequence of hypercapnia, suggesting an acute worsening without time for compensation via the renal axis, which usually occurs over hours to days. The general principles and detailed pathophysiology of respiratory failure are beyond the scope of this article, but are well reviewed elsewhere. ${ }^{9}$

The usual arterial oxygen saturation $\left(\mathrm{SaO}_{2}\right)$ for a young adult breathing air at sea level is $94 \%-98 \%$, corresponding to $11.98-14.82 \mathrm{kPa}(89.3-110.5 \mathrm{mmHg})$, although this decreases with increasing age such that the range for those $>64$ years is $9.02-14.76 \mathrm{kPa}(67.3-110.1 \mathrm{mmHg}){ }^{10}$ While hypoxemia may be defined as any arterial $\mathrm{PaO}_{2}$ below the normal lower limit, most authors suggest a value of $<8 \mathrm{kPa}$ (60 mmHg), or $\mathrm{SaO}_{2}<90 \%$, as clinically hypoxemic because the risk of hypoxic tissue damage increases below this level. ${ }^{9}$ The normal range for $\mathrm{PaCO}_{2}$ is $4.6-6.1 \mathrm{kPa}$ (34 $46 \mathrm{mmHg}$ ) and type 2 respiratory failure is diagnosed where hypercapnia is present, even in the absence of hypoxia. ${ }^{9}$

\section{Prevalence and burden of chronic respiratory failure in COPD}

The prevalence of supplemental oxygen used for respiratory failure in stable COPD is difficult to quantify and varies widely according to the population studied. In clinical trials recruiting patients with moderate disease (forced expiratory volume in 1 second of $<70 \%$ predicted) the prevalence of oxygen use was $2 \%-4 \%,{ }^{11,12}$ by contrast, in the National Emphysema Treatment trial it was used by $>80 \%$ of patients with severe disease. ${ }^{13}$ However, there are few studies that assess unselected patients in primary care, and the true prevalence is likely to be much lower than this. One audit of COPD patients in the United Kingdom reported respiratory failure or cor pulmonale in only five of 397 patients, suggesting a prevalence closer to $1 \%$ in the wider COPD population. ${ }^{14}$ Despite this, long-term oxygen therapy still accounts for an estimated specific health care expenditure of $\$ 2.3$ billion/year in the United States alone, while the estimated $\$ 1.8$ billion cost of hospitalization and emergency visits will also be due in part to the need for acute oxygen therapy at exacerbation. ${ }^{15}$

\section{Respiratory failure during acute exacerbations of COPD}

Although most patients with stable disease are able to maintain acceptable parameters, decompensation and respiratory failure are much more common in patients hospitalized with exacerbations. In a well-characterized Spanish cohort of 2,487 patients attending the emergency department with an acute exacerbation of COPD, 50\% were hypoxemic at presentation $\left(\mathrm{SaO}_{2}<90 \%\right)$ and $57 \%$ had a $\mathrm{PaCO}_{2}$ of $>45 \mathrm{mmHg}^{7}$ In a UK audit of 9,716 patients from 232 hospitals, $20 \%$ had respiratory acidosis at presentation. ${ }^{16}$ Oxygen therapy is not always administered appropriately, however, with $24 \%$ of patients in one series being hyperoxemic on arrival to hospital; ${ }^{17}$ this will be discussed further. Data from milder community-treated exacerbations are scarce, although an observational study of outpatients treated for exacerbations from the United Kingdom found a mean drop of only $1 \%$ in oxygen saturations, ${ }^{18}$ which reflects the fact that exacerbations with hypoxemia are more severe and usually treated in hospital.

\section{Pathophysiology of respiratory failure at COPD exacerbation}

Gas exchange in COPD is complex and influenced by a number of processes, although the principal common outcome is a disruption of the normal ventilation-perfusion $(\mathrm{V} / \mathrm{Q})$ ratio in the lungs, such that the blood returning to the left atrium remains poorly oxygenated. This results in systemic hypoxemia, while alveolar hypoventilation may also result in poor elimination of carbon dioxide and consequent hypercapnia.

The optimum $\mathrm{V} / \mathrm{Q}$ ratio for gas exchange is 0.8 , although even in health there is a gravitational gradient such that the ratio is higher at the top than the bottom of the lung. Different pathological processes in COPD have opposing effects on the $\mathrm{V} / \mathrm{Q}$ ratio. ${ }^{19}$ For example, emphysematous areas of lung continue to receive adequate ventilation even though the alveolar capillary networks are destroyed; the physiological dead space prevents any significant benefit from the high V/Q ratio. Conversely, small airway inflammation and obstruction prevent adequate alveolar ventilation, reducing the V/Q ratio and potentially causing veno-venous shunting. COPD is a heterogeneous lung condition and different pathological processes predominate in different lung areas, leading to admixture of differentially oxygenated blood on return to the systemic circulation. ${ }^{19}$

A complex series of events occurs at COPD exacerbation, worsening V/Q mismatch and oxygenation. Consequent to an exacerbation trigger, usually viral or bacterial, ${ }^{20}$ airway inflammation increases rapidly, ${ }^{21}$ causing increased mucus secretion, mucosal edema, and bronchospasm. ${ }^{22}$ This causes acute worsening of expiratory airflow limitation, which, combined with tachypnea, leads to 
a damaging cycle of dynamic hyperinflation and abnormal breathing. ${ }^{23}$ These, along with other factors discussed below, markedly reduce alveolar ventilation. Changes within the pulmonary vasculature compound the situation. Pulmonary vascular resistance and pulmonary arterial pressure rise acutely at exacerbation ${ }^{24}$ and this, combined with cardiac dysfunction, ${ }^{25}$ reduces blood flow to the alveolar capillary bed. Despite this, perfusion appears to be disproportionately increased through poorly ventilated lung units, ${ }^{8}$ and this worsens systemic hypoxemia still further. These processes are summarized in Figure 1.

Hypercapnia is also an important consequence of alveolar hypoventilation in severe COPD. While most patients are able to increase their respiratory drive and minute volume to maintain sufficient alveolar ventilation in the stable state, ${ }^{22}$ these adaptive mechanisms can easily be overcome at exacerbation by the pathological processes outlined above. The presence of decompensated hypercapnia causes respiratory acidemia, which normalizes over hours to days via the buffering action of bicarbonate ions generated by the kidney. ${ }^{26}$ This carries a poor prognosis ${ }^{27}$ related to the degree of acidemia ${ }^{28}$ and that appears to be worse if the hypercapnia persists after exacerbation recovery than if it reverts to normal. ${ }^{29}$

In addition to the underlying COPD, other comorbidities that may be present also affect hypoxemia at exacerbation. Disordered sleep is common in COPD

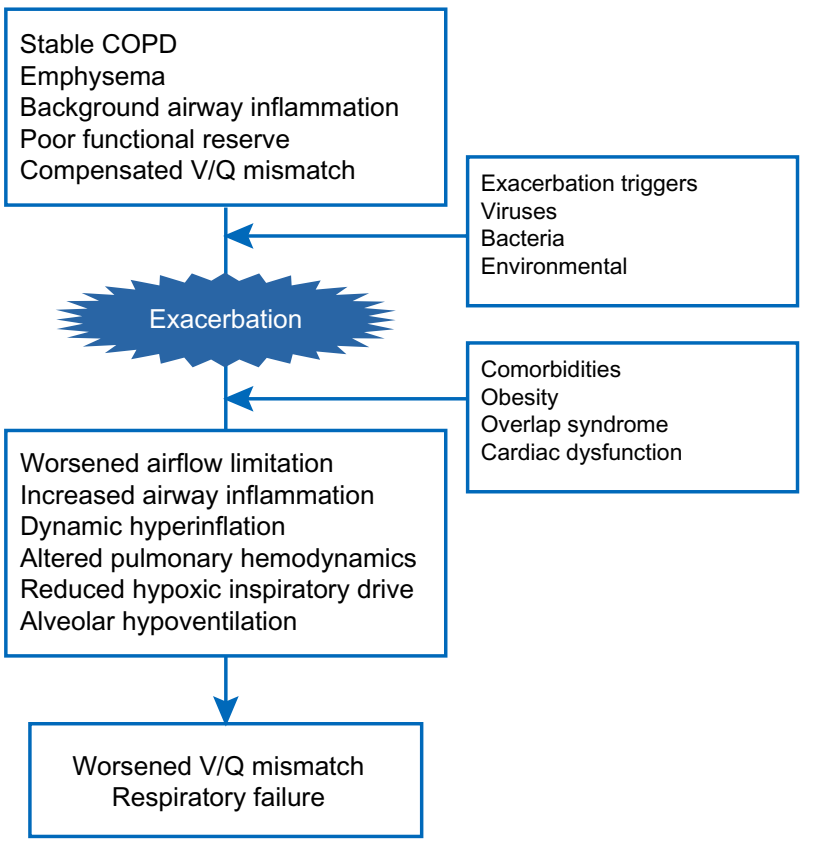

Figure I Pathological processes underlying the worsening of respiratory failure at COPD exacerbation.

Abbreviations: COPD, chronic obstructive pulmonary disease; V/Q, ventilationperfusion ratio. patients, and many experience nocturnal oxygen desaturation even in the absence of daytime hypoxemia. ${ }^{30}$ The reported prevalence of obstructive sleep apnea (OSA) in COPD (the so-called "overlap" syndrome) ${ }^{31}$ is similar to that in the general population at approximately $1 \%,{ }^{32}$ although it appears to carry a worse prognosis than COPD alone. Patients with the overlap syndrome had greater sleep desaturation ${ }^{33}$ and all-cause mortality, ${ }^{34}$ and reported more exacerbations of COPD, than did patients with either of these conditions alone. The etiology is likely multifactorial. There is a decrease in functional residual capacity when lying supine, ${ }^{35}$ and this, combined with increased airway resistance and reduced respiratory muscle tone, results in closing of small airways in dependent areas of lung. Although these changes occur physiologically to a small degree, they are much more marked in OSA. In patients with coexistent COPD, the added insult is sufficient to worsen V/Q mismatch and hypoxia, while further alveolar hypoventilation leads to reduced carbon dioxide excretion and hypercapnia. There is limited data on the effect of the overlap syndrome on exacerbations; however, recognition of OSA in these patients is important, as there is evidence that appropriate treatment with noninvasive ventilation improves mortality ${ }^{36}$ and may prevent exacerbations. ${ }^{34}$ These patients may be more prone to develop hypercapnia at exacerbation, and therefore careful titration of oxygen therapy is also necessary, as discussed further below.

Cardiac dysfunction is also common at exacerbation and is often underrecognized. In a series of 242 patients hospitalized with COPD in Scotland, $>10 \%$ fulfilled diagnostic criteria for myocardial infarction with raised cardiac enzymes, chest pain, or electrocardiogram changes when fully assessed. ${ }^{37}$ In a separate series, subclinical echocardiographic abnormalities were present in $64 \%$ of 342 patients following first hospitalization for COPD; ${ }^{25}$ right ventricular enlargement (30\%) and pulmonary hypertension (19\%) were the most-common single abnormalities, although left heart abnormalities were present in $27 \%$ of patients. There is a high prevalence of cardiac failure in $\mathrm{COPD},{ }^{38}$ and the biochemical markers of cardiac dysfunction, brain natriuretic peptide (BNP) and troponin T, predict mortality after hospitalized exacerbations. ${ }^{39,40}$ In addition, patients who experience frequent COPD exacerbations have increased cardiovascular risk, which worsens further at exacerbation, ${ }^{41}$ and this underlines the poor prognosis conferred by recurrent exacerbations. Cardiac dysfunction is therefore common and will also contribute to hypoxemia; this is important to recognize so that treatment can be optimized. 
Acute exacerbation of COPD is a clinical diagnosis, and it is important to exclude other conditions causing hypoxia and respiratory failure. For example, pulmonary embolism may be present in up to a fifth of patients presenting to hospital with COPD exacerbation, ${ }^{42}$ and this may worsen hypoxemia by causing further V/Q mismatching. Other conditions causing acidosis, reduced tissue perfusion, or increased tissue oxygen requirements, notably systemic sepsis or cardiogenic shock, may also worsen respiratory failure in COPD patients and should be treated appropriately.

\section{Beneficial effects of oxygen therapy in stable COPD}

Aside from relieving the hypoxia associated with COPD, supplemental oxygen therapy also reduces symptoms of dyspnea both in normal subjects and in those with severe COPD. ${ }^{43,44}$ A recent Cochrane meta-analysis including 431 patients across 18 studies also showed a highly significant improvement in dyspnea in nonhypoxemic COPD patients who would not otherwise meet physiological criteria for oxygen therapy. ${ }^{45}$ Breathing supplemental oxygen versus compressed air improved dyspnea and endurance during exercise in COPD patients ${ }^{46}$ and, in those patients who showed an improvement in exercise tolerance following long-term oxygen therapy (LTOT), cardiac output was also increased. ${ }^{47}$ These effects are likely related to decreased minute ventilation ${ }^{48,49}$ and decreased dynamic hyperinflation. ${ }^{50}$ Hypoxic pulmonary vasoconstriction and pulmonary hemodynamics may also be improved, ${ }^{46}$ leading to increased systemic oxygen delivery and improved respiratory muscle function. ${ }^{49}$ In addition, the flow of oxygen may stimulate upper airway and facial receptors, and this appears to reduce the intensity of dyspnea. ${ }^{51}$

Importantly, LTOT was the first therapy to demonstrate a reduction in mortality for COPD. Published in 1980, the Nocturnal Oxygen Therapy Trial ${ }^{52}$ randomized 203 patients with hypoxemic chronic lung disease to receive supplemental oxygen therapy, either continuously or overnight only, with follow-up for a minimum of 12 months. Oxygen therapy was given via nasal prongs with flow titrated to the minimum amount between 1-4 L/minute that produced a rise in $\mathrm{PaO}_{2}$. All-cause mortality in the continuous-treatment group was $52 \%$ of that in the nocturnal-only treatment group, with the difference even more marked in the subgroup with baseline hypercapnia. Shortly afterwards, the British Medical Research Council trial in the United Kingdom ${ }^{53}$ published results from 87 patients with severe COPD and hypoxemia, hypercapnia, and congestive cardiac failure who were randomized to receive oxygen (via nasal prongs at $2 \mathrm{~L} /$ minute, for a minimum of 15 hours per day) or no oxygen therapy. After 5 years of follow-up, 30/45 (67\%) of the untreated patients had died, compared to $19 / 42$ (45\%) of those who were given oxygen; arterial carbon dioxide tension and red-cell mass appeared to be useful predictors of poor prognosis. Together, these trials provide the evidence underlying the indications for the use of LTOT in severe COPD, as well as the recommendation to use LTOT for a minimum of 15 hours/day to ensure maximal benefit. However, a further trial of LTOT in patients with milder hypoxemia $\left(\mathrm{PaO}_{2}<8 \mathrm{kPa}[60 \mathrm{mmHg}]\right)$ showed no mortality benefit. ${ }^{54}$ Therapy with LTOT should therefore be restricted to hypoxemic patients with $\mathrm{PaO}_{2}<7.3 \mathrm{kPa}(55 \mathrm{mmHg}$ ), or $<8 \mathrm{kPa}$ $(60 \mathrm{mmHg})$ in the presence of complications including pulmonary hypertension, polycythemia, or peripheral edema. ${ }^{55}$ "Ambulatory" oxygen therapy may also be given to patients for use during exercise or activities of daily living, and while short-term studies show improved exercise performance in COPD, ${ }^{56}$ no survival benefit has been demonstrated.

Uncertainty remains regarding the use of LTOT in patients with isolated exercise desaturation, or only moderate hypoxemia at rest, and given the scale of LTOT use in COPD there is therefore a pressing need for further evidence. It is hoped that the Long-term Oxygen Treatment Trial, ${ }^{57}$ which aims to recruit over 1,000 participants with COPD and moderate resting hypoxemia or exercise desaturation, will answer some of these questions.

\section{Oxygen therapy at acute exacerbation of COPD}

Supplemental oxygen delivered at moderate concentrations is usually adequate to overcome the hypoxia associated with COPD exacerbations, with the main risk being the long-recognized induction of hypercapnia. ${ }^{58}$ Despite this, high-flow oxygen has long been the standard treatment for acutely distressed patients, and until relatively recently this was also the case in COPD, especially in prehospital care. However, the risks of injudicious oxygen administration in these patients are now well recognized. We outline here the rationale and guidance for the appropriate use of oxygen during COPD exacerbations, as well as strategies for oxygen delivery and ventilatory support.

\section{Oxygen-induced hypercapnia and hyperoxia at COPD exacerbation}

One important consequence of oxygen therapy is a worsening of hypercapnia in susceptible patients, and this has long 
been recognized. In 1949, case reports were first published of patients with chronic cor pulmonale in whom administration of high concentrations of oxygen induced neurological changes, including fatal coma and transient increases in intracranial pressure; ${ }^{59}$ hypercapnia was hypothesized to result from reduced minute ventilation (VE) resulting from reduced hypoxic stimulus to breathe.$^{60}$ This widely held view was challenged by a study of patients with severe COPD and hypercapnia before and after breathing in 100\% oxygen for 20 minutes. ${ }^{61}$ Although VE decreased transiently, after 15 minutes it was again similar to control values on room air; despite this, there was a significant rise in $\mathrm{PaCO}_{2}$ values that was not correlated to changes in $\mathrm{VE}$, and this was attributed to increased V/Q mismatching within the lungs, possibly due to the reversal of hypoxic vasoconstriction increasing perfusion of poorly ventilated lung units. However, this was investigated more recently using the multiple inert-gas elimination technique in 22 patients during an exacerbation of COPD. ${ }^{62}$ Intrapulmonary $\mathrm{V} / \mathrm{Q}$ defects were similar in the 12 patients who developed hypercapnia with supplemental oxygen as in those who did not, although alveolar dead space increased in the hypercapnic patients. Importantly, VE also fell by approximately $20 \%$ in the hypercapnic patients. Respiratory muscle fatigue, also thought to be a factor, appears now to only occur at a late stage, and reductions in ventilation may also reflect a shallower breathing pattern. ${ }^{58}$

A further potential mechanism underlying oxygen-induced hypercapnia results from changes in the $\mathrm{CO}_{2}$-hemoglobin dissociation curve as the $\mathrm{PaO}_{2}$ increases. Oxygenated hemoglobin has a lower carbon dioxide binding capacity than does deoxygenated hemoglobin, and as the proportion of oxygenated hemoglobin increases there is a consequent rightward shift of the $\mathrm{CO}_{2}$-hemoglobin dissociation curve. ${ }^{63}$ This is known as the Haldane effect, and it results in an increase in $\mathrm{PaCO}_{2}$. While this is usually overcome by increasing VE, patients with severe COPD are often unable to do this and hypercapnia may worsen. This may explain up to $25 \%$ of the total $\mathrm{PaCO}_{2}$ increase due to oxygen administration. ${ }^{61}$

Oxygen-induced hypercapnia at COPD exacerbation is therefore due to a complex combination of factors and remains incompletely understood. The associated risk, however, is now well recognized. Many studies have focused on the oxygen therapy given at the point of prehospital care, usually by a treating paramedic crew during assessment and transport to hospital, and this appears to be particularly important. In a retrospective case series of nearly 1,000 patients in the United Kingdom, 20\% had respiratory acidosis on presentation to hospital and this was associated with an increased risk for subsequent tracheal intubation. ${ }^{64}$ The $\mathrm{pH}$ was inversely correlated with the $\mathrm{PaO}_{2}$, and more than half of hyperoxemic patients $\left(\mathrm{PaO}_{2}>13.3 \mathrm{kPa}\right)$ were acidotic, reflecting the role of overoxygenation in the prehospital setting. Where respiratory acidosis is present, the degree of acidosis correlates to mortality. ${ }^{65}$ Similarly, one retrospective audit of prehospital oxygen therapy given to 211 patients with acute exacerbations of COPD found that those treated with oxygen at a concentration of $\geq 28 \%$ were significantly more acidotic, with significantly higher partial pressures of carbon dioxide, than those in whom controlled oxygen therapy was administered ${ }^{66}$ In one series of 254 patients presenting via ambulance with acute COPD exacerbation, ${ }^{17}$ hyperoxemia at presentation carried an odds ratio of 9.17 (95\% confidence interval $[\mathrm{CI}]=4.08-20.6)$ over normoxemia for a composite of serious adverse outcomes (including hypercapnic respiratory failure), compared to only $2.16(95 \%$ CI $=1.11-4.20)$ for hypoxemia. Further indirect evidence is provided by a large anonymized audit of arterial blood gas samples in hospital, which found oxygen saturations above the recommended $92 \%$ in $72 \%$ of hypercapnic samples, suggesting that oxygen control is poor. ${ }^{67}$ Although hypoxia may be more acutely dangerous than hypercapnia, hyperoxia therefore also carries significant excess risk.

A further consideration in hypercapnic patients treated with high oxygen concentrations is the phenomenon of rebound hypoxia upon withdrawal of supplemental oxygen. This occurs because oxygen and carbon dioxide displace each other from the limited space within the alveoli according to their relative partial pressures, as described by the alveolar gas equation. ${ }^{9}$ In the presence of a very high alveolar $\mathrm{PaO}_{2}$ (as seen when breathing a high concentration of supplemental oxygen), systemic oxygenation is maintained even as the $\mathrm{PaCO}_{2}$ rises to a level higher than it was when the patient was breathing room air. The human body stores more carbon dioxide than oxygen, and if the supplemental oxygen is abruptly withdrawn there may be a sharp fall in the alveolar $\mathrm{PaO}_{2}$ as the remaining carbon dioxide displaces the (now lower-pressure) oxygen. The result is a fall in arterial $\mathrm{PaO}_{2}$, which can be precipitous and may cause death by acute arterial hypoxemia even though the $\mathrm{PaCO}_{2}$ is stable or improving. ${ }^{68}$ For this reason, oxygen therapy should always be stepped down gradually. ${ }^{9}$

Despite compelling observational data, until relatively recently there has been a lack of high-quality evidence to directly demonstrate the benefits of titrated oxygen therapy over high-concentration oxygen. In 2010, Austin et al ${ }^{69}$ carried out the first large, well-conducted study of titrated 
oxygen therapy in prehospital care for suspected COPD exacerbations. In a cluster randomized trial, with individual paramedics as the unit of randomization, titrated oxygen therapy (via nasal prongs with the goal of maintaining saturations between $88 \%-92 \% ; 32$ paramedics) or the standard care of high-flow oxygen delivered via face mask (30 paramedics) was administered to patients; 214 patients were included in the intent-to-treat analysis, with 97 in the titrated-oxygen arm and 117 in the high-flow oxygen arm. In spite of lapses in adherence to the oxygen-titration protocol, there was a $78 \%$ reduction in mortality for those patients with confirmed COPD, as well as reduced rates of respiratory acidosis and hypercapnia.

There is now therefore strong evidence that titrating oxygen therapy to alleviate hypoxia while avoiding hyperoxia is the correct approach to oxygen therapy in COPD patients who are at high risk of hypercapnic respiratory acidosis.
Until these patients are identified by arterial blood gas analysis, titrating oxygen therapy in all patients is prudent.

\section{Administration of oxygen therapy}

The key to achieving appropriate levels of oxygenation is using controlled oxygen therapy, with the patient's oxygen level monitored and the supplemental oxygen therapy titrated to achieve acceptable saturations. This approach is summarized in Figure 2. Titration can be achieved either by altering the oxygen flow rate or, with certain delivery devices, administering a mixture of air and oxygen in set proportions such that the patient breathes in a known fraction of inspired oxygen $\left(\mathrm{FiO}_{2}\right)$. The principal modes of delivery are described below.

Nasal cannulae are perhaps the simplest mode of administering low-to-moderate concentrations of inspired oxygen and have considerable advantages over standard face masks. The

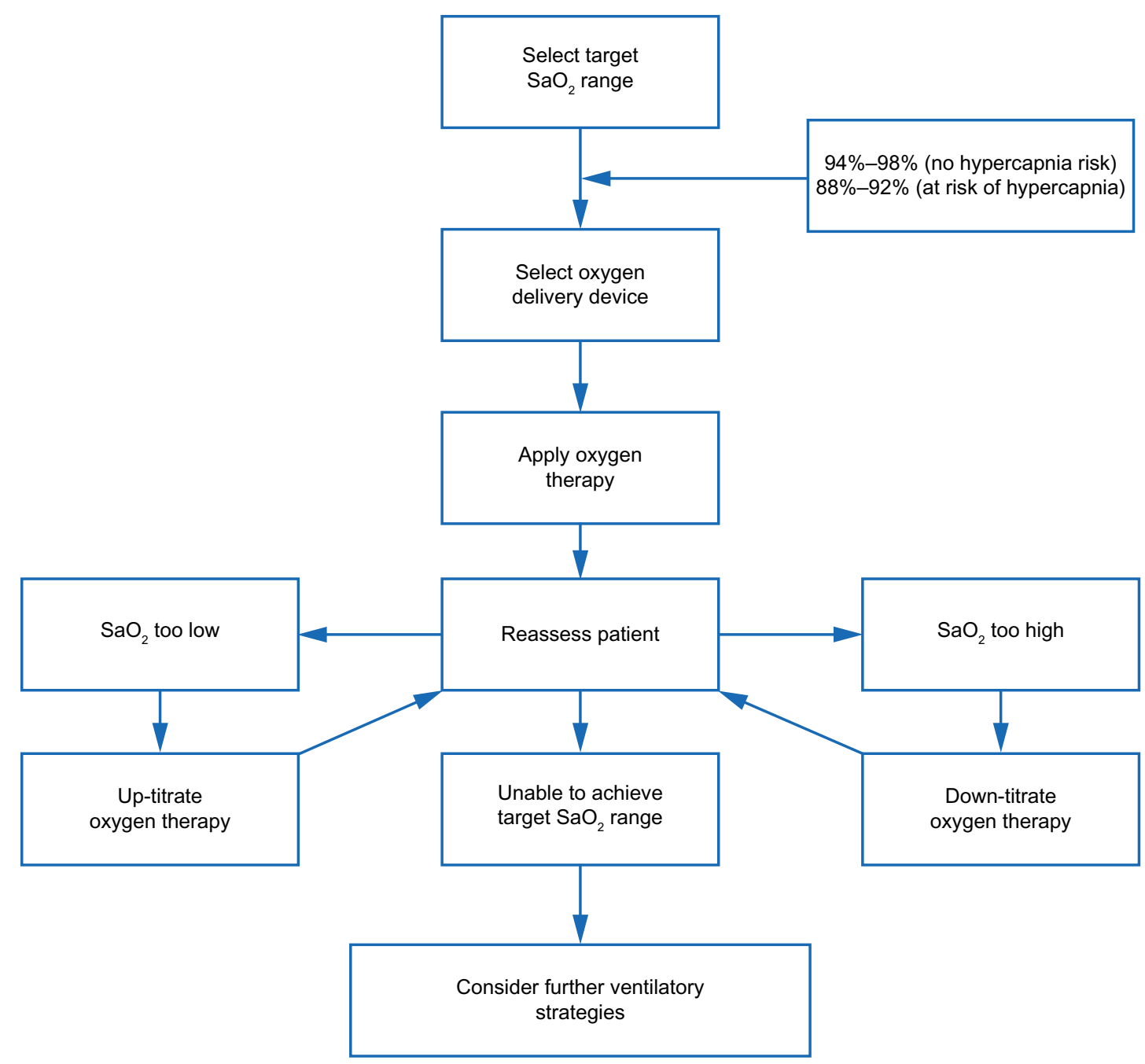

Figure 2 General principles of titrated oxygen therapy. 
short cannulas deliver oxygen directly to the nasopharynx, reducing dead space and inspiratory resistance, and they can deliver a range of oxygen flow rates from 1-6 L/minute, corresponding to $\mathrm{FiO}_{2}$ values of approximately $24 \%-50 \%$. No face mask is required and patients can therefore eat and speak while wearing their oxygen, and the cannulas are less likely than face masks to fall off or become dislodged by facial movement. ${ }^{70}$ Unsurprisingly, patients prefer cannulas to face masks, and this improves compliance with oxygen therapy. ${ }^{71}$ In addition, low-flow oxygen therapy can be continued via nasal cannulas during the administration of air-driven nebulizers for hypercapnic or acidotic patients..$^{55}$ However there are also disadvantages to nasal cannulas. Some patients experience nasal dryness or discomfort, particularly at higher flow rates. In addition, the $\mathrm{FiO}_{2}$ is affected by a multitude of patient factors, including mouth breathing, degree of nasal congestion, and the respiratory rate and minute volume. These factors may also change in the same patient at different times (for example, while eating). The use of nasal cannulas should therefore target a specific oxygen saturation level, with ongoing monitoring and titration of the oxygen flow rate to achieve this. Nasal cannulas are not recommended for the acutely unwell COPD patient, in whom accurate control of $\mathrm{FiO}_{2}$ is critical. ${ }^{9}$ However, once stability is achieved, nasal cannulas with oxygen flow rates titrated to target oxygen saturations represent the simplest and most-acceptable method of administering controlled oxygen therapy.

Simple face masks are able to deliver a higher concentration of inspired oxygen than nasal cannulas, usually between $40 \%-60 \%$. The exact $\mathrm{FiO}_{2}$ is highly variable, however, and there is a risk of rebreathing carbon dioxide at low flow rates. In addition, the concentration of $\mathrm{O}_{2}$ administered is inversely related to minute volume; if this falls and the oxygen flow rate remains constant (for example if the patient becomes drowsy due to oxygen-induced $\mathrm{CO}_{2}$ narcosis), the concentration of oxygen inspired via the mask will increase, further exacerbating the problem. These problems can be partially circumvented by using a non-rebreathing face mask, which has an oxygen reservoir bag attached; at high oxygen flow rates an $\mathrm{FiO}_{2}$ of $60 \%-90 \%$ can be delivered. Even here, however, the exact $\mathrm{FiO}_{2}$ is highly variable and dependent on the patient's minute volume. Even in COPD exacerbations, oxygenation to a safe level is usually achievable with an $\mathrm{FiO}_{2}$ of $<60 \%$, and for this reason these masks are not recommended for patients at risk of hypercapnic respiratory failure where controlled oxygen therapy is necessary. ${ }^{9}$

In 1960, Moran Campbell introduced a simple system that was able to entrain air into an oxygen stream across differing flow rates, with the amount of air added increasing as the flow of oxygen increased but the proportions remaining equal. ${ }^{72}$ Although the risks of excess oxygen therapy in patients with cor pulmonale had been well recognized, up to this point oxygen therapy could only be controlled by giving it intermittently alternated with periods on room air, a practice likened to "bringing a drowning man to the surface - occasionally." Venturi system, as it came to be known, allowed the constant delivery of a fixed concentration of oxygen to the patient. Crucially, this could be delivered at higher flow rates for tachypneic patients in whom the minute volume might otherwise exceed the available oxygen flow. Each valve is manufactured to deliver only a specific $\mathrm{FiO}_{2}$, with valves for $24 \%, 28 \%$, $35 \%, 40 \%$, and $60 \%$ usually available, and a minimum oxygen flow rate, above which the resulting air-oxygen mixture will correspond to the intended ratios, is specified. The Venturi system must be used with a face mask and therefore is subject to the usual disadvantages, including intrusiveness to patients, preventing eating and conversation, and being more prone to dislodge, but remains the preferred method for controlled oxygen administration in the emergency situation. ${ }^{9}$

The principle of controlled oxygen therapy is to target the patient's oxygen saturations within a range rather than at a specific $\mathrm{FiO}_{2}$. This is because the patient factors affecting $\mathrm{SaO}_{2}$ are dynamic and will change over time; a fixed $\mathrm{FiO}_{2}$ will not be responsive to these changing demands. Oxygen levels should be maintained at a safe level while avoiding hyperoxemia that would increase the risk of hypercapnia. Historically, there has been some debate as to what a "safe" level of hypoxemia is. Early investigators reported memory loss and cognitive difficulties in normal subjects at $\mathrm{PaO}_{2}$ levels $<45 \mathrm{mmHg}(6.0 \mathrm{kPa}){ }^{74}$ with levels $<20 \mathrm{mmHg}$ $(2.7 \mathrm{kPa})$ incompatible with life. ${ }^{75}$ Patients with COPD are able to acclimatize to even quite a severe degree of chronic hypoxia, however, and maintaining $\mathrm{PaO}_{2}>50 \mathrm{mmHg}$ $(6.7 \mathrm{kPa})$ is sufficient to prevent immediate death,${ }^{76}$ although oxygen therapy should aim to maintain a safe level above this in order to preserve normal cognitive function and prevent transient desaturations. ${ }^{76}$ The usual lower $\mathrm{PaO}_{2}$ limit for targeted oxygen therapy is $55 \mathrm{mmHg}(7.3 \mathrm{kPa})$, used as the entry criteria for the LTOT trials and subsequently ratified by consensus committee. ${ }^{77}$ In practice, real-time monitoring of $\mathrm{PaO}_{2}$ is not usually possible and therefore a target $\mathrm{SaO}_{2}$ range of $88 \%-92 \%$ is now generally accepted for those patients at risk of hypercapnia. Allowing for individual variations in the oxygen dissociation curve, this will correct hypoxia to a safe level and minimize the risk of oxygen-induced hypercapnia. 
Hypercapnia at COPD exacerbation is unusual in that it does not occur in all patients, even those with resting baseline hypercapnia; some patients may suffer recurrent hypercapnic episodes while others may only ever have isolated hypoxemia. Without arterial blood gas analysis, identifying those patients with hypercapnia is not possible. For this reason, current clinical guidance recommends that all patients with respiratory failure in the context of a diagnosis or history suggestive of COPD receive oxygen therapy targeted to $88 \%-92 \%$ until hypercapnia has been excluded by arterial blood gas analysis. ${ }^{9}$ Some patients are extremely oxygen-sensitive, with even very small amounts of supplemental oxygen sufficient to worsen hypercapnia, and these patients may need a lower target saturation range. However, if the $\mathrm{PaCO}_{2}$ is normal, oxygen therapy may target the usual saturation range of $94 \%-98 \%$, although many COPD patients may have a lower stable $\mathrm{SaO}_{2}$, such that chasing this target is not usually necessary unless the patient is unwell.

Following initiation of oxygen therapy, close observation and reassessment of the patient is key. Patients suffering acute COPD exacerbations can be extremely unwell and, particularly in the early stages following presentation, their condition can change extremely quickly. Regular assessment should include not only their respiratory rate, oxygen saturations, and other physiological measurements, but also their conscious level, as any depression of consciousness may suggest incipient carbon dioxide narcosis. As the patient improves, the oxygen should be reduced such that the upper limit of the target range is not breached. Supplemental oxygen therapy should be treated as a medication and prescribed on the treatment chart in the same way as other pharmacological agents. Prescriptions should include information regarding the delivery device, oxygen flow rate, and target oxygen saturation range, with instructions on what action to take if these parameters are exceeded in either direction.

It is important to remember that oxygen therapy during acute exacerbations of COPD is a supportive measure only and must be accompanied by treatment of the underlying COPD exacerbation. In most cases this will involve inhaled or nebulized bronchodilators, antibiotics, and systemic corticosteroids, as appropriate. ${ }^{55}$

\section{Further ventilatory strategies}

Unless the patient is in extremis, adequate oxygenation using one of the methods above is usually possible for COPD patients who have type I respiratory failure without hypercapnia. However, the patient with hypercapnic respiratory failure and acidosis may prove more complicated, and hypercapnia may progress despite treatment of the exacerbation and adequately controlled oxygen therapy. In these patients it may become impossible to adequately maintain even minimal oxygenation without further hypercapnia and potential coma, and further ventilatory support may be needed.

The respiratory stimulant doxapram has been used for many years as a means of avoiding endotracheal intubation and invasive positive-pressure ventilation. It works via stimulation of central and peripheral chemoreceptors, with the result of increasing tidal volume and minute ventilation. ${ }^{78}$ This improves the excretion of carbon dioxide, allowing correction of hypoxia without worsening hypercapnia. However, the pharmacokinetics are not predictable and therefore a constant infusion is required, with titration to dose response. It is slightly better than placebo at preventing blood-gas deterioration in the first hours of therapy, ${ }^{79}$ but has since been superseded by noninvasive ventilation (NIV). Doxapram is now recommended for use only when NIV is not available..$^{55}$

Until NIV was introduced, endotracheal intubation and mechanical ventilation was the only remaining option for patients who failed best medical therapy. This carries significant risk, and many patients with very severe underlying COPD are deemed too frail to undergo the procedure. There has therefore long been a need for methods of ventilatory support that avoid the need for sedation and intubation. Noninvasive ventilators were developed in the 1980s to deliver positive airway pressure via a face mask, and these may either be pressure preset to deliver differential pressures in inspiration and expiration, or be volume preset to deliver specific volumes. ${ }^{80,81}$ The pressure is delivered by air compression, and supplemental oxygen may also be administered; newer devices are able to deliver a specified oxygen concentration, while other devices entrain oxygen with the air, resulting in a variable but unknown oxygen concentration. Nebulized bronchodilators may also be administered through the tubing, and the apparatus has now evolved to be portable and simple to use. The mode of action is multifactorial and involves resting of the respiratory muscles, reversal of atelectasis with recruitment of lung units, and improved tidal volume. ${ }^{82}$ The net result is an increase in minute volume and reduction in the work of breathing, with increased carbon dioxide excretion and reversal of hypercapnia. ${ }^{83}$

Early reports in acute COPD exacerbations showed that, compared to historical controls, the apparatus was effective at reducing $\mathrm{PaCO} 2$, improving acidosis and oxygenation, and avoiding the need for mechanical ventilation. ${ }^{80}$ The first prospective randomized controlled trials followed shortly and 
confirmed striking benefits of NIV in reducing intubation, length of hospital stay, and in-hospital mortality, as well as a host of physiological parameters, compared to standard treatment. ${ }^{84,85}$ There is now a wealth of further evidence to support these conclusions, ${ }^{86}$ and NIV has become the accepted standard of care for patients with type 2 respiratory failure $(\mathrm{pH}<7.35$ and $\mathrm{PaCO}_{2}>6 \mathrm{kPa}$ ) due to acute exacerbation of COPD despite controlled oxygen and best medical treatment. ${ }^{87}$

NIV has many advantages. With appropriate expertise and a compliant patient, it is relatively simple to set up and allows the concurrent administration of oxygen and nebulized bronchodilators. Although some patients are unable to tolerate the tight-fitting mask, most do manage and the apparatus allows for breaks to be taken for eating and other activities. There are some contraindications to the use of NIV, particularly for patients who are unable to maintain their own airway due to obstruction or reduced conscious level, in life-threatening hypoxemia, or in the presence of undrained pneumothorax. ${ }^{88}$ However, in patients who would not be suitable candidates for endotracheal intubation and where NIV is the decided ceiling of care, it may be tried even in the presence of some of these contraindications. Regardless, clear contingency plans regarding whether or not to proceed to tracheal intubation in the event of treatment failure should always be in place prior to starting NIV, and those patients with severe respiratory acidosis $(\mathrm{pH}<7.26)$ should be managed in a high-dependency area and with a low threshold for intubation if appropriate.$^{87}$ More detailed guidance on the use of NIV is available elsewhere. ${ }^{87,88}$

\section{Current guidance for oxygen therapy in acute exacerbations of COPD}

As the risks and optimal strategies for oxygen therapy have become clearer, consensus guidelines have been written to formalize best practice. From the United Kingdom, the British Thoracic Society Guideline for emergency oxygen therapy ${ }^{9}$ provides highly detailed guidance on the delivery of oxygen therapy in COPD and other conditions. Other national and international guidance statements on COPD, including those from the Global Initiative for Chronic Obstructive Lung Disease (GOLD) ${ }^{89}$ American Thoracic Society and European Respiratory Society, ${ }^{90}$ and the National Institute for Clinical Excellence ${ }^{55}$ also include broad recommendations for the use of supplemental oxygen therapy during COPD exacerbations.

\section{Current practice and strategies for changing behavior}

The first step toward improving standards is to define the targets for optimal care. There are now nationally and internationally agreed guidelines, described above, and this has allowed an assessment of current practice and identification of targets for improvement.

The recent European COPD Audit ${ }^{91}$ examined in-hospital care against ten standards derived from the 2010 GOLD guidance on COPD management. ${ }^{89}$ Data were available from 384 hospitals in 13 countries, for 16,018 patients admitted with exacerbations of COPD. Of these, $85 \%$ of patients were given controlled oxygen therapy, $82 \%$ had arterial blood gas analysis performed on admission, and $51 \%$ received NIV as recommended, although there were wide regional variations. Although the delivery of NIV was highlighted as a specific area for improvement, controlled oxygen therapy was not correctly administered in a substantial number of cases. Even where oxygen is prescribed, deficiencies may still be identified. A large multicenter audit of inpatient oxygen therapy in Portugal found that although oxygen was prescribed in $93 \%$ of cases, the majority specified a fixed flow rate rather than target oxygen saturations, and the prescription was only completed in $12 \%$; in any case, $23 \%$ of patients were not receiving the prescribed therapy. ${ }^{92}$ It should be noted that these audits have only focused on the provision of oxygen after the patient is admitted to hospital. Many patients are still given high concentrations of oxygen during prehospital care, arriving at hospital hyperoxemic and/or hypercapnic, ${ }^{64-66}$ and it is in this acute setting that instituting correct oxygen management is most crucial.

The next logical step is to address how the provision of oxygen therapy for these patients may be improved. Simple interventions may change behavior: for example, in one retrospective series in England, issuing 28\% Venturi masks to ambulance crews assisted in reducing the proportion of patients receiving high-flow oxygen prehospital. ${ }^{66}$ Standardized care "bundles" have been shown to reduce mortality across a variety of conditions by improving in-hospital care, ${ }^{93}$ and implementing a simple standardized package of recommendations for COPD exacerbations at the emergency department of one large teaching hospital significantly improved compliance with treatment guidelines, notably increasing the correct provision of oxygen therapy from $76 \%$ to $96 \% .{ }^{94}$ In addition, the move toward comprehensively prescribing oxygen should provide a simple framework to guide staff caring for the patient. Perhaps paramount, however, is the education of health care professionals, particularly the doctors, nurses, and paramedics who are responsible for administering oxygen therapy to patients with COPD. ${ }^{95}$ Hospitals should institute local policies to improve education and practice, and these should be subject to rigorous audit and reevaluation..$^{55}$ 
Improving the education of patients may also be a factor. A recent study of patients hospitalized with COPD exacerbations showed variable awareness of the symptoms leading up to an exacerbation, which delayed symptom reporting and may therefore have increased the severity at presentation. ${ }^{96}$ In addition, patients who are known to be at risk of hypercapnic respiratory failure should be given oxygen "alert cards," $" 97$ which warn any treating clinicians, particularly paramedics, that they should be given controlled rather than high-concentration oxygen therapy. ${ }^{9}$

\section{Conclusion}

There is clear evidence that the correct use of supplemental oxygen therapy during exacerbations of COPD is an important factor that can strongly influence outcomes, and we have sought to outline this here. Future research may focus on new delivery strategies to improve the titration of oxygen therapy $^{98}$ as well as new therapies to treat the underlying COPD. In the meantime, we must ensure that the knowledge already available is translated into clinical practice and that best practice is followed. This will undoubtedly improve the treatment given to these patients.

\section{Disclosure}

The authors report no conflicts of interest in this work.

\section{References}

1. Vestbo J, Hurd SS, Agustí AG, et al. Global strategy for the diagnosis, management, and prevention of chronic obstructive pulmonary disease: GOLD executive summary. Am J Respir Crit Care Med. 2013;187(4):347-365.

2. Donaldson GC, Seemungal TA, Bhowmik A, Wedzicha JA. Relationship between exacerbation frequency and lung function decline in chronic obstructive pulmonary disease. Thorax. 2002;57(10):847-852.

3. Seemungal TA, Donaldson GC, Paul EA, Bestall JC, Jeffries DJ, Wedzicha JA. Effect of exacerbation on quality of life in patients with chronic obstructive pulmonary disease. Am J Respir Crit Care Med. 1998;157(5 Pt 1):1418-1422.

4. Soler-Cataluña JJ, Martínez-García MA, Román Sánchez P, Salcedo E, Navarro M, Ochando R. Severe acute exacerbations and mortality in patients with chronic obstructive pulmonary disease. Thorax. 2005;60(11):925-931.

5. Suissa S, Dell'Aniello S, Ernst P. Long-term natural history of chronic obstructive pulmonary disease: severe exacerbations and mortality. Thorax. 2012;67(11):957-963.

6. West JB. Causes of and compensations for hypoxemia and hypercapnia. Compr Physiol. 2011;1(3):1541-1553.

7. Quintana JM, Esteban C, Unzurrunzaga A, et al; IRYSS-COPD group. Predictive score for mortality in patients with COPD exacerbations attending hospital emergency departments. BMC Med. 2014;12:66.

8. Barberà JA, Roca J, Ferrer A, et al. Mechanisms of worsening gas exchange during acute exacerbations of chronic obstructive pulmonary disease. Eur Respir J. 1997;10(6):1285-1291.

9. O'Driscoll BR, Howard LS, Davison AG; British Thoracic Society. BTS guideline for emergency oxygen use in adult patients. Thorax. 2008; 63 Suppl 6:vi1-vi68.
10. Crapo RO, Jensen RL, Hegewald M, Tashkin DP. Arterial blood gas reference values for sea level and an altitude of 1,400 meters. Am J Respir Crit Care Med. 1999;160(5 Pt 1):1525-1531.

11. Tashkin DP, Celli B, Senn S, et al; UPLIFT Study Investigators. A 4-year trial of tiotropium in chronic obstructive pulmonary disease. N Engl J Med. 2008;359(15):1543-1554.

12. Wise RA, Anzueto A, Cotton D, et al; TIOSPIR Investigators. Tiotropium Respimat inhaler and the risk of death in COPD. $N$ Engl $J$ Med. 2013;369(16):1491-1501.

13. Martinez FJ, Foster G, Curtis JL, et al; NETT Research Group. Predictors of mortality in patients with emphysema and severe airflow obstruction. Am J Respir Crit Care Med. 2006;173(12):1326-1334.

14. Jones RC, Dickson-Spillmann M, Mather MJ, Marks D, Shackell BS. Accuracy of diagnostic registers and management of chronic obstructive pulmonary disease: the Devon primary care audit. Respir Res. 2008;9:62.

15. Ward MM, Javitz HS, Smith WM, Bakst A. Direct medical cost of chronic obstructive pulmonary disease in the USA. Respir Med. 2000;94(11):1123-1129.

16. Roberts CM, Stone RA, Buckingham RJ, Pursey NA, Lowe D; National Chronic Obstructive Pulmonary Disease Resources and Outcomes Project Implementation Group. Acidosis, non-invasive ventilation and mortality in hospitalised COPD exacerbations. Thorax. 2011;66(1):43-48.

17. Cameron L, Pilcher J, Weatherall M, Beasley R, Perrin K. The risk of serious adverse outcomes associated with hypoxaemia and hyperoxaemia in acute exacerbations of COPD. Postgrad Med J. 2012;88(1046):684-689.

18. Hurst JR, Donaldson GC, Quint JK, Goldring JJ, Patel AR, Wedzicha JA. Domiciliary pulse-oximetry at exacerbation of chronic obstructive pulmonary disease: prospective pilot study. BMC Pulm Med. 2010;10:52.

19. Cooper CB, Celli B. Venous admixture in COPD: pathophysiology and therapeutic approaches. COPD. 2008;5(6):376-381.

20. Wedzicha JA, Singh R, Mackay AJ. Acute COPD exacerbations. Clin Chest Med. 2014;35(1):157-163.

21. Bhowmik A, Seemungal TA, Sapsford RJ, Wedzicha JA. Relation of sputum inflammatory markers to symptoms and lung function changes in COPD exacerbations. Thorax. 2000;55(2):114-120.

22. O'Donnell DE, Parker CM. COPD exacerbations . 3: Pathophysiology. Thorax. 2006;61(4):354-361.

23. O'Donnell DE, Laveneziana P. The clinical importance of dynamic lung hyperinflation in COPD. COPD. 2006;3(4):219-232.

24. Chaouat A, Naeije R, Weitzenblum E. Pulmonary hypertension in COPD. Eur Respir J. 2008;32(5):1371-1385.

25. Freixa X, Portillo K, Paré C, et al; PAC-COPD Study Investigators. Echocardiographic abnormalities in patients with COPD at their first hospital admission. Eur Respir J. 2013;41(4):784-791.

26. Schwartz WB, Brackett NC Jr, Cohen JJ. The response of extracellular hydrogen ion concentration to graded d-egrees of chronic hypercapnia: the physiologic limits of the defense of ph. J Clin Invest. 1965;44:291-301.

27. Matkovic Z, Huerta A, Soler N, et al. Predictors of adverse outcome in patients hospitalised for exacerbation of chronic obstructive pulmonary disease. Respiration. 2012;84(1):17-26.

28. Plant PK, Owen JL, Elliott MW. Early use of non-invasive ventilation for acute exacerbations of chronic obstructive pulmonary disease on general respiratory wards: a multicentre randomised controlled trial. Lancet. 2000;355(9219):1931-1935.

29. Costello R, Deegan P, Fitzpatrick M, McNicholas WT. Reversible hypercapnia in chronic obstructive pulmonary disease: a distinct pattern of respiratory failure with a favorable prognosis. Am J Med. 1997;102(3):239-244.

30. McSharry DG, Ryan S, Calverley P, Edwards JC, McNicholas WT. Sleep quality in chronic obstructive pulmonary disease. Respirology. 2012;17(7):1119-1124.

31. Flenley DC. Sleep in chronic obstructive lung disease. Clin Chest Med. 1985;6(4):651-661. 
32. McNicholas WT, Verbraecken J, Marin JM. Sleep disorders in COPD: the forgotten dimension. Eur Respir Rev. 2013;22(129):365-375.

33. Sanders MH, Newman AB, Haggerty CL, et al; Sleep Heart Health Study. Sleep and sleep-disordered breathing in adults with predominantly mild obstructive airway disease. Am J Respir Crit Care Med. 2003;167(1):7-14.

34. Marin JM, Soriano JB, Carrizo SJ, Boldova A, Celli BR. Outcomes in patients with chronic obstructive pulmonary disease and obstructive sleep apnea: the overlap syndrome. Am J Respir Crit Care Med 2010;182(3):325-331.

35. Verbraecken J, McNicholas WT. Respiratory mechanics and ventilatory control in overlap syndrome and obesity hypoventilation. Respir Res. 2013;14:132.

36. Machado MC, Vollmer WM, Togeiro SM, et al. CPAP and survival in moderate-to-severe obstructive sleep apnoea syndrome and hypoxaemic COPD. Eur Respir J. 2010;35(1):132-137.

37. McAllister DA, Maclay JD, Mills NL, et al. Diagnosis of myocardial infarction following hospitalisation for exacerbation of COPD. Eur Respir J. 2012;39(5):1097-1103.

38. de Miguel Díez J, Chancafe Morgan J, Jiménez García R. The association between COPD and heart failure risk: a review. Int J Chron Obstruct Pulmon Dis. 2013;8:305-312.

39. Chang CL, Robinson SC, Mills GD, et al. Biochemical markers of cardiac dysfunction predict mortality in acute exacerbations of COPD. Thorax. 2011;66(9):764-768.

40. Abroug F, Ouanes-Besbes L, Nciri N, et al. Association of left-heart dysfunction with severe exacerbation of chronic obstructive pulmonary disease: diagnostic performance of cardiac biomarkers. Am J Respir Crit Care Med. 2006;174(9):990-996.

41. Patel AR, Kowlessar BS, Donaldson GC, et al. Cardiovascular risk, myocardial injury, and exacerbations of chronic obstructive pulmonary disease. Am J Respir Crit Care Med. 2013;188(9):1091-1099.

42. Rizkallah J, Man SF, Sin DD. Prevalence of pulmonary embolism in acute exacerbations of COPD: a systematic review and metaanalysis Chest. 2009;135(3):786-793.

43. Chronos N, Adams L, Guz A. Effect of hyperoxia and hypoxia on exercise-induced breathlessness in normal subjects. Clin Sci (Lond). 1988;74(5):531-537.

44. Swinburn CR, Mould H, Stone TN, Corris PA, Gibson GJ Symptomatic benefit of supplemental oxygen in hypoxemic patients with chronic lung disease. Am Rev Respir Dis. 1991;143(5 Pt 1): 913-915.

45. Uronis H, McCrory DC, Samsa G, Currow D, Abernethy A. Symptomatic oxygen for non-hypoxaemic chronic obstructive pulmonary disease. Cochrane Database Syst Rev. 2011CD006429.

46. Dean NC, Brown JK, Himelman RB, Doherty JJ, Gold WM, Stulbarg MS. Oxygen may improve dyspnea and endurance in patients with chronic obstructive pulmonary disease and only mild hypoxemia. Am Rev Respir Dis. 1992;146(4):941-945.

47. Morrison DA, Stovall JR. Increased exercise capacity in hypoxemic patients after long-term oxygen therapy. Chest. 1992;102(2): 542-550.

48. O'Donnell DE, Bain DJ, Webb KA. Factors contributing to relief of exertional breathlessness during hyperoxia in chronic airflow limitation. Am J Respir Crit Care Med. 1997;155(2):530-535.

49. Bye PT, Esau SA, Levy RD, et al. Ventilatory muscle function during exercise in air and oxygen in patients with chronic air-flow limitation. Am Rev Respir Dis. 1985;132(2):236-240.

50. O’Donnell DE, D’Arsigny C, Fitzpatrick M, Webb KA. Exercise hypercapnia in advanced chronic obstructive pulmonary disease: the role of lung hyperinflation. Am J Respir Crit Care Med. 2002;166(5): 663-668.

51. Manning HL, Schwartzstein RM. Pathophysiology of dyspnea. N Engl J Med. 1995;333(23):1547-1553.

52. Continuous or nocturnal oxygen therapy in hypoxemic chronic obstructive lung disease: a clinical trial. Nocturnal Oxygen Therapy Trial Group. Ann Intern Med. 1980;93(3):391-398.
53. Long term domiciliary oxygen therapy in chronic hypoxic cor pulmonale complicating chronic bronchitis and emphysema. Report of the Medical Research Council Working Party. Lancet. 1981;1(8222):681-686.

54. Górecka D, Gorzelak K, Sliwiński P, Tobiasz M, Zieliński J. Effect of long-term oxygen therapy on survival in patients with chronic obstructive pulmonary disease with moderate hypoxaemia. Thorax. 1997;52(8):674-679.

55. National Institute for Health and Clinical Excellence. Chronic Obstructive Pulmonary Disease: Management of Chronic Obstructive Pulmonary Disease in Adults in Primary and Secondary Care (Partial Update); NICE Clinical Guideline 101. London, UK: National Institute for Health and Clinical Excellence; 2010. Avaliable from: http://www. nice.org.uk/guidance/cg101/resources/guidance-chronic-obstructivepulmonary-disease-pdf. Accessed September 13, 2014.

56. Bradley JM, Lasserson T, Elborn S, Macmahon J, O'neill B. A systematic review of randomized controlled trials examining the short-term benefit of ambulatory oxygen in COPD. Chest. 2007;131(1):278-285.

57. Stoller JK, Panos RJ, Krachman S, Doherty DE, Make B; Long-term Oxygen Treatment Trial Research Group. Oxygen therapy for patients with COPD: current evidence and the long-term oxygen treatment trial. Chest. 2010;138(1):179-187.

58. Calverley PM. Respiratory failure in chronic obstructive pulmonary disease. Eur Respir J Suppl. 2003;47:26s-30s.

59. Davies CE, Mackinnon J. Neurological effects of oxygen in chronic cor pulmonale. Lancet. 1949;2(6585):883-885.

60. Donald K, Simpson T, Mcmichael J, Lennox B. Neurological effects of oxygen. Lancet. 1949;254(6588):1056-1057.

61. Aubier M, Murciano D, Milic-Emili J, et al. Effects of the administration of $\mathrm{O} 2$ on ventilation and blood gases in patients with chronic obstructive pulmonary disease during acute respiratory failure. Am Rev Respir Dis. 1980;122(5):747-754.

62. Robinson TD, Freiberg DB, Regnis JA, Young IH. The role of hypoventilation and ventilation-perfusion redistribution in oxygen-induced hypercapnia during acute exacerbations of chronic obstructive pulmonary disease. Am J Respir Crit Care Med. 2000;161(5):1524-1529.

63. Abdo WF, Heunks LM. Oxygen-induced hypercapnia in COPD: myths and facts. Crit Care. 2012;16(5):323.

64. Plant PK, Owen JL, Elliott MW. One year period prevalence study of respiratory acidosis in acute exacerbations of COPD: implications for the provision of non-invasive ventilation and oxygen administration. Thorax. 2000;55(7):550-554.

65. Jeffrey AA, Warren PM, Flenley DC. Acute hypercapnic respiratory failure in patients with chronic obstructive lung disease: risk factors and use of guidelines for management. Thorax. 1992;47(1):34-40.

66. Durrington HJ, Flubacher M, Ramsay CF, Howard LS, Harrison BD. Initial oxygen management in patients with an exacerbation of chronic obstructive pulmonary disease. QJM. 2005;98(7):499-504.

67. O'Driscoll BR, Rudenski A, Turkington PM, Howard LS. An audit of hypoxaemia, hyperoxaemia, hypercapnia and acidosis in blood gas specimens. Eur Respir J. 2012;39(1):219-221.

68. Kane B, Turkington PM, Howard LS, Davison AG, Gibson GJ, O'Driscoll BR. Rebound hypoxaemia after administration of oxygen in an acute exacerbation of chronic obstructive pulmonary disease. $B M J$. 2011;342:d1557.

69. Austin MA, Wills KE, Blizzard L, Walters EH, Wood-Baker R. Effect of high flow oxygen on mortality in chronic obstructive pulmonary disease patients in prehospital setting: randomised controlled trial. BMJ. 2010;341:c5462.

70. Nolan KM, Winyard JA, Goldhill DR. Comparison of nasal cannulae with face mask for oxygen administration to postoperative patients. Br J Anaesth. 1993;70(4):440-442.

71. Costello RW, Liston R, McNicholas WT. Compliance at night with low flow oxygen therapy: a comparison of nasal cannulae and Venturi face masks. Thorax. 1995;50(4):405-406

72. Campbell EJ. A method of controlled oxygen administration which reduces the risk of carbon-dioxide retention. Lancet. 1960;2(7140):12-14. 
73. Gibson GJ. Moran Campbell and clinical science. Thorax. 2004;59(9): 737-740.

74. Boycott AE, Haldane JS. The effects of low atmospheric pressures on respiration. J Physiol. 1908;37(5-6):355-377.

75. Campbell EJ. Respiratory failure. Br Med J. 1965;1(5448):1451-1460.

76. Murphy R, Driscoll P, O'Driscoll R. Emergency oxygen therapy for the COPD patient. Emerg Med J. 2001;18(5):333-339.

77. Petty TL, Casaburi R. Recommendations of the Fifth Oxygen Consensus Conference. Writing and Organizing Committees. Respir Care. 2000; 45(8):957-961.

78. Calverley PM, Robson RH, Wraith PK, Prescott LF, Flenley DC. The ventilatory effects of doxapram in normal man. Clin Sci (Lond). 1983;65(1):65-69.

79. Greenstone M, Lasserson TJ. Doxapram for ventilatory failure due to exacerbations of chronic obstructive pulmonary disease. Cochrane Database Syst Rev. 2003CD000223.

80. Brochard L, Isabey D, Piquet J, et al. Reversal of acute exacerbations of chronic obstructive lung disease by inspiratory assistance with a face mask. N Engl J Med. 1990;323(22):1523-1530.

81. Meecham Jones DJ, Paul EA, Grahame-Clarke C, Wedzicha JA. Nasal ventilation in acute exacerbations of chronic obstructive pulmonary disease: effect of ventilator mode on arterial blood gas tensions. Thorax. 1994;49(12):1222-1224.

82. Meyer TJ, Hill NS. Noninvasive positive pressure ventilation to treat respiratory failure. Ann Intern Med. 1994;120(9):760-770.

83. Meecham Jones DJ, Paul EA, Jones PW, Wedzicha JA. Nasal pressure support ventilation plus oxygen compared with oxygen therapy alone in hypercapnic COPD. Am J Respir Crit Care Med. 1995;152(2):538-544.

84. Brochard L, Mancebo J, Wysocki M, et al. Noninvasive ventilation for acute exacerbations of chronic obstructive pulmonary disease. $N$ Engl J Med. 1995;333(13):817-822.

85. Kramer N, Meyer TJ, Meharg J, Cece RD, Hill NS. Randomized, prospective trial of noninvasive positive pressure ventilation in acute respiratory failure. Am J Respir Crit Care Med. 1995;151(6):1799-1806.

86. Ram FS, Picot J, Lightowler J, Wedzicha JA. Non-invasive positive pressure ventilation for treatment of respiratory failure due to exacerbations of chronic obstructive pulmonary disease. Cochrane Database Syst Rev. 2004CD004104.

87. Roberts CM, Brown JL, Reinhardt AK, et al. Non-invasive ventilation in chronic obstructive pulmonary disease: management of acute type 2 respiratory failure. Clin Med. 2008;8(5):517-521.
88. British Thoracic Society Standards of Care Committee. Non-invasive ventilation in acute respiratory failure. Thorax. 2002;57(3): 192-211.

89. Global Initiative for Chronic Obstructive Lung Disease (GOLD). Global Strategy for the Diagnosis, Management, and Prevention of Chronic Obstructive Pulmonary Disease. Vancouver, WA: GOLD; 2010. Available from: http://www.goldcopd.org/uploads/users/files/ GOLDReport_April112011.pdf. Accessed September 13, 2014.

90. Qaseem A, Wilt TJ, Weinberger SE, et al; American College of Physicians; American College of Chest Physicians; American Thoracic Society; European Respiratory Society. Diagnosis and management of stable chronic obstructive pulmonary disease: a clinical practice guideline update from the American College of Physicians, American College of Chest Physicians, American Thoracic Society, and European Respiratory Society. Ann Intern Med. 2011;155(3):179-191.

91. Roberts CM, Lopez-Campos JL, Pozo-Rodriguez F, Hartl S; European COPD Audit Team. European hospital adherence to GOLD recommendations for chronic obstructive pulmonary disease (COPD) exacerbation admissions. Thorax. 2013;68(12):1169-1171.

92. Neves JT, Lobão MJ; Grupo de trabalho EMO. Oxygen therapy multicentric study - a nationwide audit to oxygen therapy procedures in internal medicine wards. Rev Port Pneumol. 2012;18(2):80-85.

93. Robb E, Jarman B, Suntharalingam G, Higgens C, Tennant R, Elcock K. Using care bundles to reduce in-hospital mortality: quantitative survey. BMJ. 2010;340:c1234.

94. McCarthy C, Brennan JR, Brown L, et al. Use of a care bundle in the emergency department for acute exacerbations of chronic obstructive pulmonary disease: a feasibility study. Int $J$ Chron Obstruct Pulmon Dis. 2013;8:605-611.

95. Nippers I, Sutton A. Oxygen therapy: professional compliance with national guidelines. Br J Nurs. 2014;23(7):382-386.

96. Stone R, Lowe D, Buckingham R, Pursey N, Potter J, Roberts CM. What happens to COPD patients before an admission with exacerbation? Prim Health Care Res Dev. 2012;13(4):395-402.

97. Gooptu B, Ward L, Ansari SO, Eraut CD, Law D, Davison AG. Oxygen alert cards and controlled oxygen: preventing emergency admissions at risk of hypercapnic acidosis receiving high inspired oxygen concentrations in ambulances and A\&E departments. Emerg Med J. 2006;23(8):636-638.

98. Lellouche F, Lipes J, L'Her E. Optimal oxygen titration in patients with chronic obstructive pulmonary disease: a role for automated oxygen delivery? Can Respir J. 2013;20(4):259-261.
International Journal of COPD

\section{Publish your work in this journal}

The International Journal of COPD is an international, peer-reviewed journal of therapeutics and pharmacology focusing on concise rapid reporting of clinical studies and reviews in COPD. Special focus is given to the pathophysiological processes underlying the disease, intervention programs, patient focused education, and self management protocols.

\section{Dovepress}

This journal is indexed on PubMed Central, MedLine and CAS. The manuscript management system is completely online and includes a very quick and fair peer-review system, which is all easy to use. Visit $\mathrm{http}: / /$ www.dovepress.com/testimonials.php to read real quotes from published authors. 